\title{
Early childhood television viewing and kindergarten entry readiness
}

\author{
Linda S. Pagani ${ }^{1,2}$, Caroline Fitzpatrick ${ }^{1,2}$ and Tracie A. Barnett ${ }^{2}$
}

BACKGROUND: Using a large population-based sample, this study aims to verify whether televiewing at $29 \mathrm{mo}$, a common early childhood pastime, is prospectively associated with school readiness at 65 mo.

METHODS: Participants are a prospective longitudinal cohort of 991 girls and 1,006 boys from the Quebec Longitudinal Study of Child Development with parent-reported data on weekly hours of televiewing at 29 mo of age. We conducted a series of ordinary least-squares regressions in which children's scores on direct child assessments of vocabulary, mathematical knowledge, and motor skills, as well as kindergarten teacher reports of socioemotional functioning, were linearly regressed on early televiewing.

RESULTS: Every SD increase (1.2h) in daily televiewing at 29 mo predicted decreases in receptive vocabulary, number knowledge scores, classroom engagement, and gross motor locomotion scores, as well as increases in the frequency of victimization by classmates.

CONCLUSION: Increases in total time watching television at 29 mo were associated with subsequent decreases in vocabulary and math skills, classroom engagement (which is largely determined by attention skills), victimization by classmates, and physical prowess at kindergarten. These prospective associations, independent of key potential confounders, suggest the need for better parental awareness and compliance with existing viewing recommendations put forth by the American Academy of Pediatrics (AAP).

$\mathbf{T}$ he omnipresence of television in the background and foreground of family life has sparked questions about the possible long-term impact of young children's excessive media exposure during early childhood (1). Many parents seem unaware or unconcerned about the recommendations put forth by the AAP (2). To avoid the potential risks of overexposure, the AAP discourages televiewing during infancy and recommends not more than $2 \mathrm{~h}$ per day beyond age 2 (3).

The AAP recommendations assume that the content is of quality and developmentally appropriate $(1,3)$. Thakkar et al. (4) systematically reviewed 12 experimentally controlled trials and found that educational television programs viewed around age 3 are successful in broadening young children's knowledge, affecting their racial attitudes, and increasing their imaginativeness. They also found some evidence suggesting that viewing cartoons has a negative effect on children's attention skills. More specifically, attention seems to be negatively influenced by fast-paced, noneducational entertainment with highly stimulating audiovisual effects (5). Moreover, the first $3 \mathrm{y}$ seem to be a critical period for potential harm from viewing fastpaced television (6). One experimental study suggests negative effects of fast-paced media on the developing executive system (7). It is noteworthy that these significant risks found in naturalistic studies have only been observed with network television content, as opposed to the educational content that is often featured on public television $(5,6)$. A recent study found that $75 \%$ of content reported by parents is mostly mixed and network based, suggesting that either young children control the remote or parents are not proactive in changing channels toward more appropriate content (8). In addition, a majority of parents do not carefully monitor how much of their children's time is spent watching television $(1,2)$.

From birth to school entry, viewing time diminishes other more active and interactive endeavors at a time when brain growth and development are highly dependent on environmental stimulation through live social interaction and active play with persons and objects across different contexts $(9,10)$. It is plausible that too much screen time could reduce time spent engaging in developmentally enriching activities and tasks that require more mental effort and thus foster brain development (3). There is some indirect support for the idea that time lost is at the detriment of hands-on or socially interactive activities. First, because there are only so many waking hours in a day, more time spent televiewing might leave less time for creative play and foundational experiences that hone cognitive, socioemotional, behavioral, and motor skills (11). Second, Vandewater et al. (12) found that time spent watching television alone or with parents or siblings was linked with less time spent interacting with them in other activities. Third, televiewing is both an intellectually and a physically sedentary activity that ultimately does not hone the development of the brain's executive system and physical fitness (13). Fourth, daily amounts of televiewing are related to disrupted sleep patterns and bedtime resistance (14). Fifth, for older children, time 


\section{Articles | Paganietal.}

spent watching television is negatively associated with time spent doing homework (12). Finally, early screen-time habits forecast later childhood screen-time habits $(3,11,13)$, which could generate a time debt for other important lifestyle activities, regardless of age.

The preschool years, which culminate in kindergarten entry, represent a sensitive period in the development of cognitive, sensorimotor, and socioemotional characteristics that play a key role in eventual academic and personal success (15). As an international preoccupation, school readiness is concerned with informally learned preschool skills that culminate in the eventual ability to meet the elementary school curriculum $(9,15)$. Traditionally, school readiness is defined by how well it predicts children's achievement in later grades. This ultimately forecasts finishing high school, especially in disadvantaged populations (16). School readiness should also be concerned with preparedness to adopt healthy lifestyle skills and habits because disparities in educational attainment often translate into disparities in healthy lifestyle habits, well-being, and family social support $(17,18)$.

Several large-scale prospective longitudinal studies have sought to establish an empirically driven definition of what kindergarten factors matter the most for later achievement (19-21). The approach has generally included an exhaustive test of cognitive and behavioral characteristics that have been suggested by teaching professionals as important for being ready to learn. The findings from these studies reveal that cognitive and attention skills show the most power in forecasting later math and reading achievement. Although they have long been neglected by researchers, motor skills have finally been acknowledged as important in forecasting math and reading achievement in later grades (20-22) and many successful preschool programs have included movement as a part of their curricula (23).

Approximately one in five children show some form of developmental delay or psychopathology during the transition to formal schooling (24). Such numbers indicate not only the potential for dropout but also a life course of difficulties in social and occupational functioning (16). Therefore, ensuring that all children are prepared for school entry has become an important societal goal given the eventual socioeconomic and health implications of underachievement, lifestyle risks, and social maladjustment (15-18).

Although watching preschool programming has some merits and benefits for 3 to 5 y olds $(5,6,11)$ and exposure to physical or psychological violence should be discouraged (8), questions have been raised about whether too much televiewing has a negative influence on preparedness at kindergarten entry. Several prospective independent investigations suggest associations between early childhood television exposure and school readiness characteristics. In one study, higher levels of early televiewing were related to increases in attention problems in first grade (25). Other researchers also found negative influences on verbal and memory skills at ages 6 and 7 for each hour of televiewing before $3 y$ of age (26). Indeed, a third study has found a negative association between early televiewing and socioemotional adjustment at school entry (27). These studies, which each focus on a singular aspect of school readiness, suggest that excessive televiewing during the early years may undermine brain development and associated correlates of neurocognitive functioning such as executive functioning, emotional regulation, and sensorimotor development.

Despite the strengths of prior research, a more comprehensive study is warranted, especially using a prospective design with child development data that has served in establishing the conceptualization of school readiness. These include cognitive, behavioral, emotional, and the often neglected motor skills at school entry. In the present study, we use a population-based sample of children from a prospective longitudinal cohort study to examine the relationship between televiewing at 29 mo and cognitive, socioemotional, and motor skills at kindergarten. Outcome measures comprise data from direct child assessments and teachers. To better isolate the influence of early televiewing on child characteristics at kindergarten, we statistically control for potentially confounding child and family characteristics. It is expected that more televiewing at 29 mo will be associated with less school readiness at kindergarten.

\section{RESULTS}

Televiewing at 29 mo averaged $12.36 \mathrm{~h}$ for the entire week $(\mathrm{SD}=8.51)$. Similar to averages reported among American children, these quantities are within current recommendations of not more than $2 \mathrm{~h}$ per day beyond age 2 , assuming that the content is developmentally appropriate (3). Nevertheless, $30 \%$ of the children viewed more than $2 \mathrm{~h}$ of television per day. Children with more educated mothers experienced less exposure at 29 mo (as previously noted in refs. 8,13).

Table 1 displays the prospective association between televiewing at $29 \mathrm{mo}$ and indicators of school readiness in kindergarten. In terms of language development and number knowledge, more televiewing at 29 mo was associated with lower subsequent scores on the Peabody Picture Vocabulary Test (unstandardized $B=-0.220, P<0.000,95 \%$ confidence interval (CI) between -0.291 and -0.149 ) and the Number Knowledge Test (unstandardized $B=-0.029, P<0.000,95 \%$ CI between -0.043 and -0.015$)$. Given that a $1-S D$ increase in televiewing corresponds approximately to $1 \mathrm{~h}$ of television viewing, every additional daily hour of early childhood television exposure corresponded to an 11 and $7 \%$ unit decrease in receptive vocabulary and number knowledge scores, respectively. Higher levels of televiewing were also associated with lower scores of teacher-rated classroom engagement (unstandardized $B=-0.002, P=0.015,95 \% \mathrm{CI}$ between -0.004 and 0.000 ). More specifically, every additional daily hour of early childhood television exposure corresponded to a 5.2\% unit decrease in classroom engagement scores in kindergarten. Children who viewed more television at 29 mo had poorer performances on the locomotion subscale of the test of gross motor development (unstandardized $B=-0.024, P<0.000$, $95 \%$ CI between -0.034 and -0.014 ). Every additional hour of exposure at 29 mo corresponded to a $9 \%$ unit decrease in locomotion scores. Televiewing did not influence the object 
Table 1. Standardized regression coefficients reflecting the prospective association between televiewing at 29 mo and kindergarten school readiness characteristics

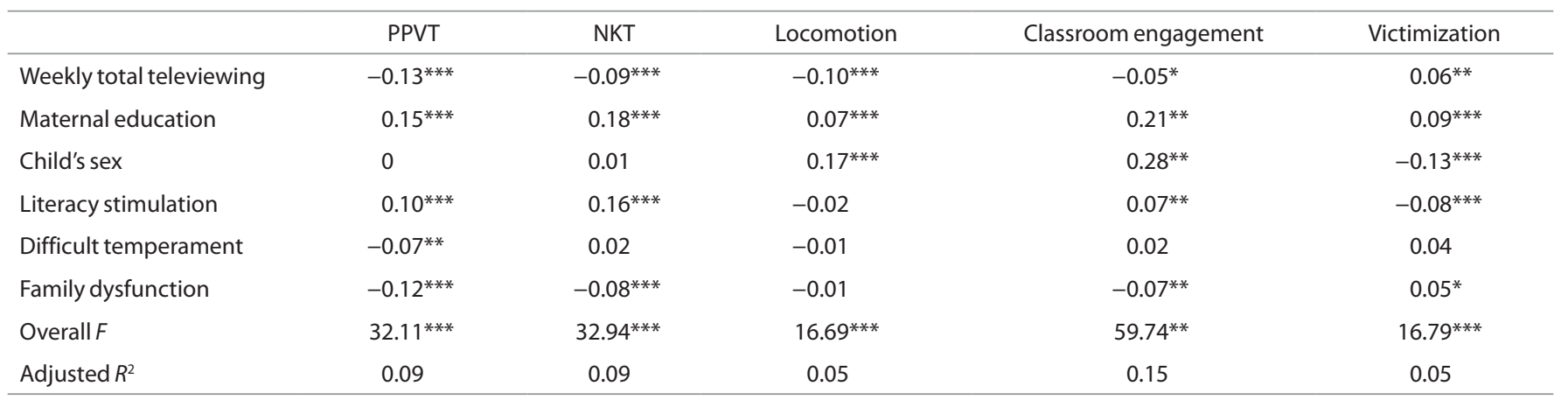

For child sex, data were dichotomized as $0=$ boy, $1=$ girl.

NKT, Number Knowledge Test; PPVT, peabody picture vocabulary test.

${ }^{*} P=0.05 ; * * 0.01 ;{ }^{* * *} P<0.001$.

control factor of gross motor development. Finally, child televiewing at 29 mo was associated with teacher-rated victimization by kindergarten classmates (unstandardized $B=0.008$, $P=0.005,95 \%$ CI between 0.002 and 0.014 ), such that each 1-h increase in early childhood exposure corresponded to a $6 \%$ unit increase in the teacher-rated measure of victimization. Televiewing at 29 mo did not significantly influence teacherrated measures of kindergarten anxiety, physical aggression, or prosocial behavior.

\section{DISCUSSION}

Early child development and school performance have long been considered integral components of clinical practice and assessment in the realm of community health care regarding children (18). Identifying modifiable factors that identify a lack of readiness for the transition to formal schooling represents an important goal for social pediatrics (17). Using a population of typically developing children followed from birth, the current study sought to verify the findings from a handful of independent studies addressing the influence of early childhood televiewing on distinct school readiness outcomes (25-27) and offers a singular and consistent approach to the television exposure predictor, outcomes, and statistical controls.

The present study is the first to suggest a prospective association between excessive early televiewing and kindergarten motor skills. Specifically, more televiewing was linked with greater difficulty in performing athletic movements such as running and shuffling by age 6 . Motor skills have recently regained attention as key elements of school readiness because they forecast better long-term reading and attentionrelated skills $(20,21)$. In the first years of life, attention and motor skills recruit common sensory systems and cortical structures in the brain (28). The results suggest that watching too much television at 29 mo may interfere with progressive interdependence in overlapping cortical structures, which eventually play a role in supporting higher-order cognitive and motor functions by kindergarten. There are several other related explanations for this finding. Televiewing is a sedentary activity that can foster habitual preferences for less physically demanding activities (12), which subsequently predict poorer health and higher BMI (29). Personal preferences might mean engaging in fewer lifestyle activities that involve running, kicking, and catching a ball, as well as playing games that develop spatial, eye-hand, and perceptive-cognitive coordination. In children, frequent physical activity is linked with proficient motor skills (30). Such processes may explain why excessive early televiewing is also prospectively associated with less explosive leg strength, an important indicator of physical capability (31). These explanations merit empirical attention.

As expected, more early childhood televiewing was subsequently associated with less developed cognitive skills in kindergarten. These results replicate the diminished literacyrelated outcomes found in one previous study (26). We also found a negative influence on number knowledge, whereas that study did not. Also, consistent with another previous study addressing the relationship between early televiewing and attention skills (25), increases in early televiewing were linked with modest subsequent decreases in classroom engagement. This result suggests that early televiewing may slightly undermine later executive function processes that regulate task orientation, productivity and autonomy, being cooperative with classmates, and carefully following rules and instructions in the classroom. As an outcome, classroom engagement is strongly related to attention (32) and represents an ecological assessment of executive function skills in typical learning contexts (21). The 29-mo televiewing predictor reflects a time of substantial brain growth in frontal regions recruited for effortful control processes $(28,33,34)$. These characteristics are ultimately associated with child achievement (19-21) and personal success in adulthood (16). The association with diminished classroom engagement suggests that excessive early televiewing may not be beneficial for the development of executive functions during a critical period in brain growth. That is, too much screen time may predispose children to inattentive and passive dispositions in learning situations over the long term (13). 


\section{Articles | Paganietal.}

In terms of children's socioemotional well-being, higher levels of early televiewing were associated with greater chances of victimization experiences such as being teased, assaulted, or insulted by other classmates, according to teachers. In a previous study, increases in televiewing time were prospectively associated with increases in both the screen time and the same victimization measure at age 10 (13). The development of peer relationships and learning to get along with others are essential elements of the kindergarten classroom experience as children prepare for transition to more formal schooling. Early televiewing in early childhood, which becomes habitual by age 10, might slow the development of necessary skills for positive and ageappropriate peer relationship formations in kindergarten. The idea that increased time spent watching television might interfere with the acquisition of social skills involving confidence and self-assertion, which play an important role in helping children effectively avoid victimization, warrants further investigation.

Overall, it is plausible that excessive televiewing might undermine the functions of the executive system that produce school readiness in children. From birth to age 5, these functions regulate and coordinate sensory processing and help in the retrieval of information from memory while children learn to engage behaviorally, read, write, do arithmetic, copy a shape, catch a ball, and jump rope $(34,35)$. During the preschool years, motor skills strongly forecast cognitive skills and vice versa (20-22). This relationship is attributable to their common recruitment of the cerebellum, basal ganglia, and prefrontal cortex (20). Like a coordinated orchestra, the executive functions play a key role in learning both cognitive and motor skills (33). That is, without self-regulated attention and goal-directed behavior, we would not have coordinated and meaningful skills in either area. Excessive viewing may displace time otherwise well spent during early childhood, and it may also reflect excessive exposure to fast-paced cartoon content, which is common among preschool viewers and clearly undermines executive functioning (7). Consequently, this likely translates into risks of less developed cognitive, motor, and classroom engagement skills at kindergarten entry.

This study is not without limitations. Foremost is that the measure of television exposure did not comprise a finely tuned scale of quantity and content of television exposure. Watching educational television, within the time constraints recommended by the AAP, has merits (3). However, watching too much television, even in cases of high-quality content, could imply too much intellectually and physically sedentary activity as compared with other developmental enriching activities for a 2 y old. Nevertheless, accounting for content would have provided a clear and compelling portrait of the influence of media usage at age 2. A second major limitation is the use of parentreported data, which, in terms of quality, is considered the "lowest-hanging fruit on the tree" (11). Finally, even if the crude assessment of screen-time exposure is justified, parent reports may significantly underestimate the true amount of young children's screen time. Until recently, researchers were unaware that children experience considerable additional television viewing in day-care settings. Parental estimates of home viewing likely do not account for this extra source, which in many cases may double the total amount of screen time. Using the same screentime measures as in this study, Christakis and Garrison (36) found that children in as many as $70 \%$ of home-based childcare settings and $36 \%$ of center-based child-care settings watch television daily as part of their planned programming. Infants and children spent $2-3 \mathrm{~h}$ watching in home-based programs and $1.5 \mathrm{~h}$ watching in center-based programs. Therefore, in light of the fact that the majority of preschool-age children receive some kind of child care, parent reports may have significantly underestimated the true amount of young children's total screen time.

As with other studies in the area, we view our results as conservative, given the different data sources for the outcome measures, and remind readers that even with such limited television predictor measures we find robust effects. This is statistically remarkable and points to a stronger effect than is suggested by the coefficients. By statistical standards, the results show modest associations, yet these are net effects that chart a developmental course that could ultimately compromise achievement, social relations, physical prowess, and preferences and habits toward a healthy lifestyle $(13,29-31,37)$. Nevertheless, when dealing with high-stakes outcomes such as school readiness and achievement, even small effect sizes can translate into important social costs when projected over a lifespan and across an entire population. The use of a prospective longitudinal design from birth onward represents a major strength because it does not depend on retrospective recall and allows the tracking of child development and health without researcher bias or interference.

School readiness has traditionally involved stimulating preschool children to prepare them for kindergarten. Children may be better served if we also focus on protecting their brains (9). Research has increasingly shown how educational attainment and health habits and status are strongly intertwined $(17,18)$. Protective factors such as knowledge transfer of AAP guidelines and inspiring parents to teach their children selfmonitoring skills can play a role in parent education and child assessment with regard to school readiness. This "ounce of prevention equals a pound of cure" approach not only bridges medicine and social science but also fuels clinical intervention, position statements, and major policy initiatives. In this vein, routine assessment of television habits likely represents a good investment by professionals who play an important role in wellness promotion and disease prevention. Because school readiness is a personal characteristic that forecasts personal and academic success well into adulthood, this study suggests that efforts be directed toward increasing parent awareness and compliance with the existing guidelines.

\section{METHODS}

\section{Participants}

Coordinated by the Institute de la Statistique du Quebec, the Quebec Longitudinal Study of Child Development originates from a randomly selected, stratified sample of 2,837 infants born between 1997 and 1998 in Québec, Canada (http://www.iamillbe.stat.gouv.qc.ca/ default_an.htm). In the early phase of the project, 93 children were deemed ineligible, 172 were untraceable because of incorrect coordinates, 14 were unreachable, and 438 refused participation. Thus, following informed consent, 2,120 infants and their families were deemed eligible for follow-up at 5, 17, and 29 mo, representing $77 \%$ 
of the eligible target population. In total, televiewing data were available for 1,999 children ( $99 \%$ of the original representative sample) in this institutional review board-approved study at the University of Montréal (Montréal, Québec, Canada).

\section{Measures: Predictor (at $29 \mathrm{mo}$ )}

The mothers were asked, "How much time per day does your child spend watching TV (including DVD and videotape viewing)?” This was asked regarding both weekday and weekend viewing. Scores reflect the total hours of weekly television exposure (weekday viewing multiplied by 5 plus weekend viewing multiplied by 2), which were then divided by 7 to give an approximate estimate of daily viewing. This measure is comparable or similar to previous population-based assessments of children's screen viewing in the home $(12,14,25-27)$, including our own $(8,13,31)$

\section{Measures: School Readiness Outcome (at $65 \mathrm{mo}$ )}

Peabody Picture Vocabulary Test. The Peabody Picture Vocabulary Test (French adaptation) (38) was administered by trained examiners to test receptive vocabulary knowledge. This test consists of 175 vocabulary items that increase in difficulty throughout the test. The French version has been standardized and is highly correlated with other French vocabulary and intelligence tests (38) and measures of academic performance (19).

Number Knowledge Test. The Number Knowledge Test (abridged version) was administered individually to children by trained examiners to test basic numeracy and early arithmetic skills (39). The Number Knowledge Test, adjusted for $5 \mathrm{y}$ olds, measures knowledge of the number sequence from 1 to 10 ; one-to-one correspondence in which a sequence is mapped onto objects being counted; the cardinal value of each number; generative rules that relate adjacent cardinal values; and that each successive number represents a set that contains more objects.

Gross motor development. Trained experimenters administered the test of gross motor development to assess child locomotion skills (i.e., running, side shuffle) and object control (i.e., catching, kicking) $(31,40)$. During this test, experimenters first demonstrated a gross motor action. Next, the child was asked to repeat the action twice. The child was given one point for each correct demonstration. A total for each subtest was then calculated by summing the scores.

Classroom engagement. This measure of classroom productivity is strongly driven by attention and memory skills $(21,41)$. Kindergarten teachers rated 7 items of classroom engagement behaviors from 1 (never) to 5 (always). A mean classroom engagement score was computed for each participant from the following items: works and plays cooperatively with other children; follows rules and instructions; follows directions; listens attentively; completes work on time; works autonomously; and works neatly and carefully $(\alpha=0.92)(32)$.

Socioemotional characteristics. Kindergarten teachers also completed the Social Behavior Questionnaire $(8,13,19,21)$, which includes several factors indicating behavioral adjustment; anxiety (4 items, $\alpha=0.77$ ); physical aggression (3 items, $\alpha=0.85$ ); prosocial behavior (3 items, $\alpha=0.85$ ); and victimization ( 3 items, $\alpha=0.77$ ). All of the Social Behavior Questionnaire items were rated on a Likert scale with response options 1 (never or not true), 2 (sometimes or somewhat true), or 3 (often or very true) and were then converted to scores ranging from 0 to 10 . Higher scores indicate a higher degree of the factor. The Social Behavior Questionnaire represents a good predictor of future socioemotional adjustment and school success $(32,42)$.

\section{Measures: Control Variables}

Maternal education. When children were $\sim 5$ mo old, mothers were asked about their highest degree obtained, from which a dichotomous maternal education variable was constructed differentiating between mothers with no high school diploma (coded as 0 ) and mothers with at least a high school diploma (coded as 1). In this sample, $15.3 \%$ had not obtained high school diplomas at the first data collection wave.

Literacy stimulation. When children were $\sim 17$ mo of age, parents were asked how often they: (i) looked through books with their children; (ii) read books with their children; and (iii) played with crayons with their children. Response options ranged from "A few times a week" or "everyday" (given a value of 1 ) to "once a week or less" (given a value of 0 ). Stimulation at home scores reflect the sum of responses across all three questions. The average stimulation score obtained by families in this sample on this variable was $2.38(\mathrm{SD}=0.76)$.

Temperament. At $\sim 17$ mo of age, parents reported on two dimensions of temperament (13): difficult (6 items, Cronbach's $\alpha=0.71$ ) or unpredictable (7 items, Cronbach's $\alpha=0.70$ ). For each dimension, responses ranged from 1 to 7 , on a 7-point Likert scale, with lower scores reflecting an easier temperament. A summary variable was then created to capture the presence of child temperament problems. Dichotomous scores were derived such that scores above the 70th percentile on each dimension were coded as 1 (reflecting substantial temperament problems) and scores below the 70th percentile were coded as 0 . A sum reflecting temperament problems was computed from dichotomized scores. Approximately half of the children received a total score of 0 (suggesting the absence of temperament problems), whereas $35.7 \%$ children received a score of 1 and $13.7 \%$ children received a score of 2 (above the 70th percentile).

Family functioning. At 65 mo, parents reported on 12 items that pertain to communication and problem solving within the family environment. Higher scores reflect more family dysfunction (43).

\section{Data Analytic Strategy}

To reduce bias resulting from nonrandom attrition, missing data were imputed using AMELIA software (developed by James Honaker, Gary King, and Matthew Blackwell at Harvard University, Cambridge, MA). A total of 100 possible data sets were generated and aggregated to maintain a more realistic estimate of observed relations among variables and SE estimates. We then estimated a series of ordinary least-squares regressions, in which indicators of school readiness measured at 65 mo were linearly regressed on televiewing at 29 mo. Each model features weekly total hours of televiewing at 29 mo while controlling for potentially confounding individual and family characteristics (maternal education, early stimulation of literacy, early child temperament, and family functioning).

\section{STATEMENT OF FINANCIAL SUPPORT}

This work was supported by the Social Science and Humanities Research Council of Canada Grant 861-2007-1005.

Disclosure: None to declare.

\section{REFERENCES}

1. Certain LK, Kahn RS. Prevalence, correlates, and trajectory of television viewing among infants and toddlers. Pediatrics 2002;109:634-42.

2. Funk JB, Brouwer J, Curtiss K, McBroom E. Parents of preschoolers: expert media recommendations and ratings knowledge, media-effects beliefs, and monitoring practices. Pediatrics 2009;123:981-8.

3. American Academy of Pediatrics. Children, adolescents, and television. Pediatrics 2011;107:423-6.

4. Thakkar RR, Garrison MM, Christakis DA. A systematic review for the effects of television viewing by infants and preschoolers. Pediatrics 2006;118:2025-31.

5. Geist EA, Gibson M. The effect of network and public television programs on 4- and 5-year-olds' ability to attend to educational tasks. J Instructional Psychol 2000;27:250-61.

6. Zimmerman FJ, Christakis DA. Associations between content types of early media exposure and subsequent attentional problems. Pediatrics 2007;120:986-92.

7. Lillard AS, Peterson J. The immediate impact of different types of television on young children's executive function. Pediatrics 2011;128:644-9.

8. Fitzpatrick C, Barnett T, Pagani LS. Early exposure to media violence and later child adjustment. J Dev Behav Pediatr 2012;33:291-7.

9. Shonkoff JP. Protecting brains, not simply stimulating minds. Science 2011;333:982-3.

10. Meltzoff AN, Kuhl PK, Movellan J, Sejnowski TJ. Foundations for a new science of learning. Science 2009;325:284-8. 
11. Christakis DA. The effects of infant media usage: what do we know and what should we learn? Acta Paediatr 2009;98:8-16.

12. Vandewater EA, Bickham DS, Lee JH. Time well spent? Relating television use to children's free-time activities. Pediatrics 2006;117:e181-91.

13. Pagani LS, Fitzpatrick C, Barnett TA, Dubow E. Prospective associations between early childhood television exposure and academic, psychosocial, and physical well-being by middle childhood. Arch Pediatr Adolesc Med 2010;164:425-31.

14. Owens J, Maxim R, McGuinn M, Nobile C, Msall M, Alario A. Television-viewing habits and sleep disturbance in school children. Pediatrics 1999;104:e27.

15. High PC; American Academy of Pediatrics Committee on Early Childhood, Adoption, and Dependent Care and Council on School Health. School readiness. Pediatrics 2008;121:e1008-15.

16. Heckman JJ. Skill formation and the economics of investing in disadvantaged children. Science 2006;312:1900-2.

17. Schor EL. The future pediatrician: promoting children's health and development. J Pediatr 2007;151:Suppl 5:S11-6.

18. Zuckerman B, Halfon N. School readiness: an idea whose time has arrived. Pediatrics 2003;111(6 Pt 1):1433-6.

19. Duncan GJ, Dowsett CJ, Claessens A, et al. School readiness and later achievement. Dev Psychol 2007;43:1428-46.

20. Grissmer D, Grimm KJ, Aiyer SM, Murrah WM, Steele JS. Fine motor skills and early comprehension of the world: two new school readiness indicators. Dev Psychol 2010;46:1008-17.

21. Pagani LS, Fitzpatrick C, Archambault I, Janosz M. School readiness and later achievement: a French Canadian replication and extension. Dev Psychol 2010;46:984-94.

22. Cameron CE, Brock LL, Murrah WM, et al. Fine motor skills and executive function both contribute to kindergarten achievement. Child Dev 2012;83:1229-44.

23. Lillard A. Montessori: The Science Behind the Genius. New York, NY: Oxford University Press, 2005.

24. Carter AS, Wagmiller RJ, Gray SA, McCarthy KJ, Horwitz SM, BriggsGowan MJ. Prevalence of DSM-IV disorder in a representative, healthy birth cohort at school entry: sociodemographic risks and social adaptation. J Am Acad Child Adolesc Psychiatry 2010;49:686-98.

25. Christakis DA, Zimmerman FJ, DiGiuseppe DL, McCarty CA. Early television exposure and subsequent attentional problems in children. Pediatrics 2004;113:708-13.

26. Zimmerman FJ, Christakis DA. Children's television viewing and cognitive outcomes: a longitudinal analysis of national data. Arch Pediatr Adolesc Med 2005;159:619-25.

27. Mistry KB, Minkovitz CS, Strobino DM, Borzekowski DL. Children’s television exposure and behavioral and social outcomes at 5.5 years: does timing of exposure matter? Pediatrics 2007;120:762-9.
28. Marsh R, Gerber AJ, Peterson BS. Neuroimaging studies of normal brain development and their relevance for understanding childhood neuropsychiatric disorders. J Am Acad Child Adolesc Psychiatry 2008;47:1233-51.

29. DuRant RH, Baranowski T, Johnson M, Thompson WO. The relationship among television watching, physical activity, and body composition of young children. Pediatrics 1994;94(4 Pt 1):449-55.

30. Wrotniak BH, Epstein LH, Dorn JM, Jones KE, Kondilis VA. The relationship between motor proficiency and physical activity in children. Pediatrics 2006;118:e1758-65.

31. Fitzpatrick C, Pagani LS, Barnett TA. Early childhood television viewing predicts explosive leg strength and waist circumference by middle childhood. Int J Behav Nutr Phys Act 2012;9:87.

32. Pagani LS, Fitzpatrick C, Parent S. Relating kindergarten attention to subsequent developmental pathways of classroom engagement in elementary school. J Abnorm Child Psychol 2012;40:715-25.

33. Garon N, Bryson SE, Smith IM. Executive function in preschoolers: a review using an integrative framework. Psychol Bull 2008;134: $31-60$.

34. Blair C, Razza RP. Relating effortful control, executive function, and false belief understanding to emerging math and literacy ability in kindergarten. Child Dev 2007;78:647-63.

35. Diamond A. Close interrelation of motor development and cognitive development and of the cerebellum and prefrontal cortex. Child Dev 2000;71:44-56.

36. Christakis DA, Garrison MM. Preschool-aged children's television viewing in child care settings. Pediatrics 2009;124:1627-32.

37. Andersen RE, Crespo CJ, Bartlett SJ, Cheskin LJ, Pratt M. Relationship of physical activity and television watching with body weight and level of fatness among children: results from the Third National Health and Nutrition Examination Survey. JAMA 1998;279:938-42.

38. Dunn LM, Thériault-Whalen CM, Dunn LM. Peabody Picture Vocabulary Test-Revised: French adaptation. Toronto, Canada: Psycan, 1993.

39. Okamoto Y, Case R. Exploring the microstructure of children's central conceptual structures in the domain of number. Monogr Soc Res Child Dev 1996;61:27-58.

40. Ulrich D. Test of Gross Motor Development. Austin, TX: Pro-Ed, 2000.

41. Dobkin PL, Tremblay RE, Mâsse LC, Vitaro F. Individual and peer characteristics in predicting boys' early onset of substance abuse: a seven-year longitudinal study. Child Dev 1995;66:1198-214.

42. Pagani L, Tremblay RE, Vitaro F, Boulerice B, McDuff P. Effects of grade retention on academic performance and behavioral development. Dev Psychopathol 2001;13:297-315.

43. Epstein NB, Baldwin LM, Bishop DS. The McMaster family assessment device. J Marital Fam Ther 1983;9:171-80. 